\title{
SNOWPACK model simulations for snow in Hokkaido, Japan
}

\author{
Hiroyuki HIRASHIMA, ${ }_{1}^{1}$ Kouighi NISHIMURA, ${ }^{2}$ Emiko BABA, ${ }^{1}$ Aкiniro HACHIKUBO, ${ }^{3}$ \\ Miahael LEHNING ${ }^{4}$ \\ ${ }^{1}$ Institute of Low Temperature Science, Hokkaido University, Sapporo 060-0819, Japan \\ E-mail: hirashi@hucc.hokudai.ac.jp \\ ${ }^{2}$ Nagaoka Institute of Snow and Ice Studies, National Research Institute for Earth Science and Disaster Prevention, STA Suyoshi, Nagaoka \\ 940-0821, Japan \\ ${ }^{3}$ Kitami Institute of Technology, Koen-cho 165, Kitami 090-8507, Japan \\ ${ }^{4}$ WSL Swiss Federal Institute for Snow and Avalanche Research SLF, Flüelastrasse 11, CH-7260 Davos-Dorf, Switzerland
}

\begin{abstract}
Numerical simulations using SNOWPACK, a snow-cover model, were carried out to confirm the model's applicability to conditions in Hokkaido, Japan, where temperatures are fairly low and for 3 months the snow surface is usually dry except during occasional periods of rain or above-freezing temperatures. The simulations were conducted for Sapporo, Kitami and Niseko using meteorological data, and the results were compared with the observed snow profiles. In Sapporo, snow-profile observations were carried out every day for two winters. In Niseko, one of the most popular ski resorts in Japan, an avalanche accident occurred on 28 January 1998 and a snow pit was dug through the fracture line the next morning. The simulated snow profiles agreed fairly well with the observed ones. However, near the surface we observed depth hoar, which can be an important factor in avalanche release after successive snowfalls, that the model did not reproduce distinctly. Extending the model's metamorphism laws with an expression of depth-hoar formation under a large temperature gradient, as formulated from an experiment by Fukuzawa and Akitaya (1993), the model reproduced the depth hoar adequately.
\end{abstract}

\section{INTRODUCTION}

In mountainous terrain, avalanches threaten lives and damage residential areas, agricultural land and transportation lines. One type of this phenomenon, the well-known slab avalanche, is caused by shear failure and fracture propagation within the snowpack parallel to the slope. Shear failure results when a weak layer with low shear strength succumbs under a large load. Numerical simulation can be used to simulate the existence of weak layers and predict avalanche danger.

SNOWPACK, developed by the Swiss Federal Institute for Snow and Avalanche Research, is a one-dimensional numerical model of the snow cover. It has been used operationally in the Swiss Alps to predict snowpack settlement, layering, surface energy exchange and mass balance (Bartelt and Lehning, 2002; Lehning and others, 2002a, b). This model estimates snow profiles (e.g. snow type, snow temperature, water content and density) by using meteorological data obtained by automatic weather stations (AWSs). Lundy and others (2001) applied the SNOWPACK model for a continental (Rocky Mountains) climate and showed its validation employing familiar statistical methods. On the other hand, Lehning and others (2001) developed an original snow-profile comparison method for the quantification of agreement between modeled and observed snow profiles.

The purpose of this study is to carry out numerical simulations using SNOWPACK to confirm the model's applicability to Hokkaido, Japan, where temperatures are fairly low and for 3 months the snow surface is usually dry except during occasional periods of rain or above-freezing temperatures. The assessment serves to improve the model's reproducibility and versatility, and to evaluate the capability of the model to improve avalanche warning. Simulations were conducted at Sapporo (winter 1996/97), Kitami (winter 2000/01) and Niseko (winter 1997/98) using the meteorological data, and the results were compared with observed snow profiles.

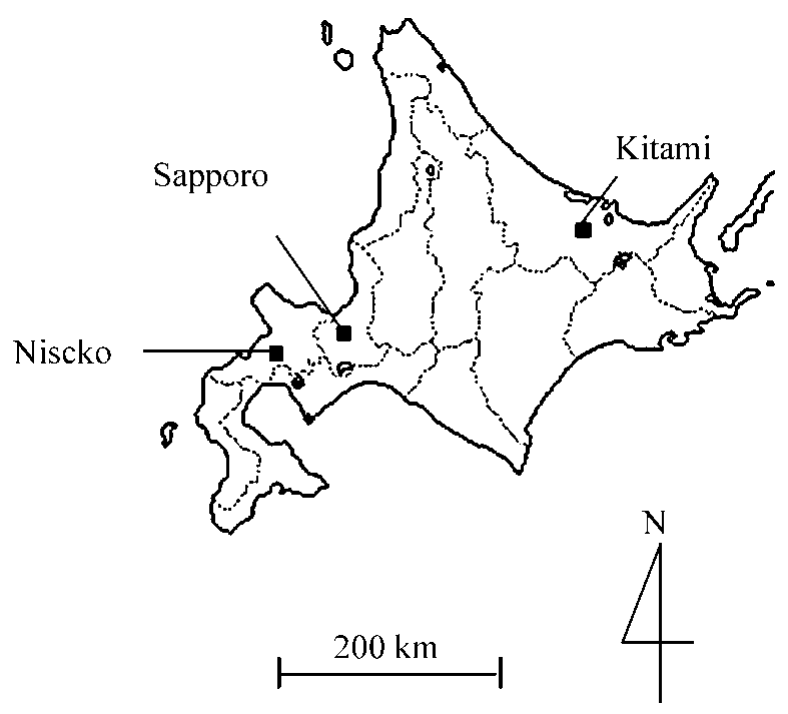

Fig. 1. Location of the study sites on the island of Hokkaido, Japan. 

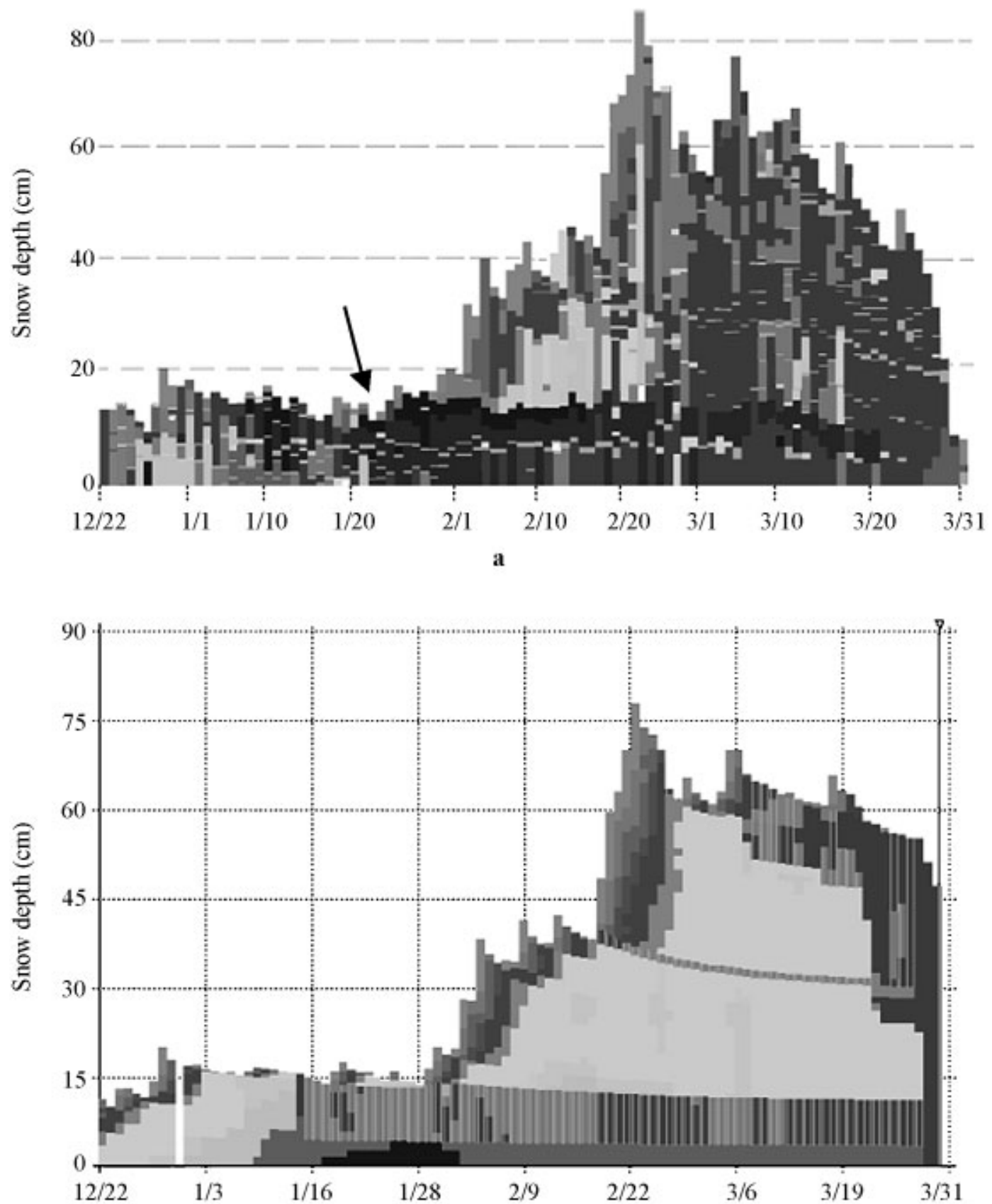

b

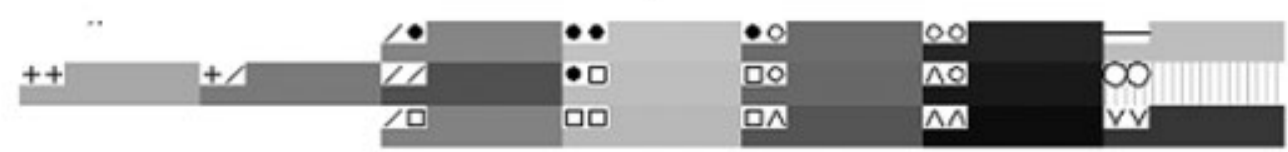

Fig. 2. Snow profiles at Sapporo in 1996/97 (dates are month/day). The key at the foot of the figure shows the relationship between shading and grain types. (+) is new snow; (/) is partly decomposed snow; $(\bullet)$ is rounded grains; $(\square)$ is faceted grains; $(\wedge)$ is depth hoar; and (o) is melt-freeze grains. (a) Daily observed snow profiles. Black arrow indicates the depth-hoar formation of snow surface. (b) Simulated snow profiles.

\section{OBSERVATIONS}

Figure 1 shows the location of the study sites. Sites are located at Sapporo (15 m a.s.l.; $43^{\circ} 04^{\prime} \mathrm{N}, 141^{\circ} 20^{\prime} \mathrm{E}$ ), Niseko (930 $\mathrm{m}$ a.s.l.; $42^{\circ} 52^{\prime} \mathrm{N}, 140^{\circ} 52^{\prime} \mathrm{E}$ ) and Kitami (85 m a.s.l.; $43^{\circ} 48^{\prime} \mathrm{N}, 143^{\circ} 53^{\prime} \mathrm{E}$ ). At each site, meteorological data (e.g. air temperature, relative humidity, wind speed, wind direction, snow surface temperature, solar radiation and snow depth) were measured every $30 \mathrm{~min}$.

Snow-pit observations were carried out, either every day (at Sapporo) or at intervals of several days (at Niseko and Kitami). All snow-pit observation sites are uniformly flat and located within $50 \mathrm{~m}$ of the weather stations. Density was measured with a vertical resolution of $3 \mathrm{~cm}$ with a $100 \mathrm{~cm}^{3}$ snow sampler. Snow grain-size and type in each layer were determined using a crystal screen and magnifying glass. The snow type was classified based on the international morphological classification proposed by Colbeck and others (1990) and characterized by two basic grain shapes in each layer. In this study, our focus was mainly on 


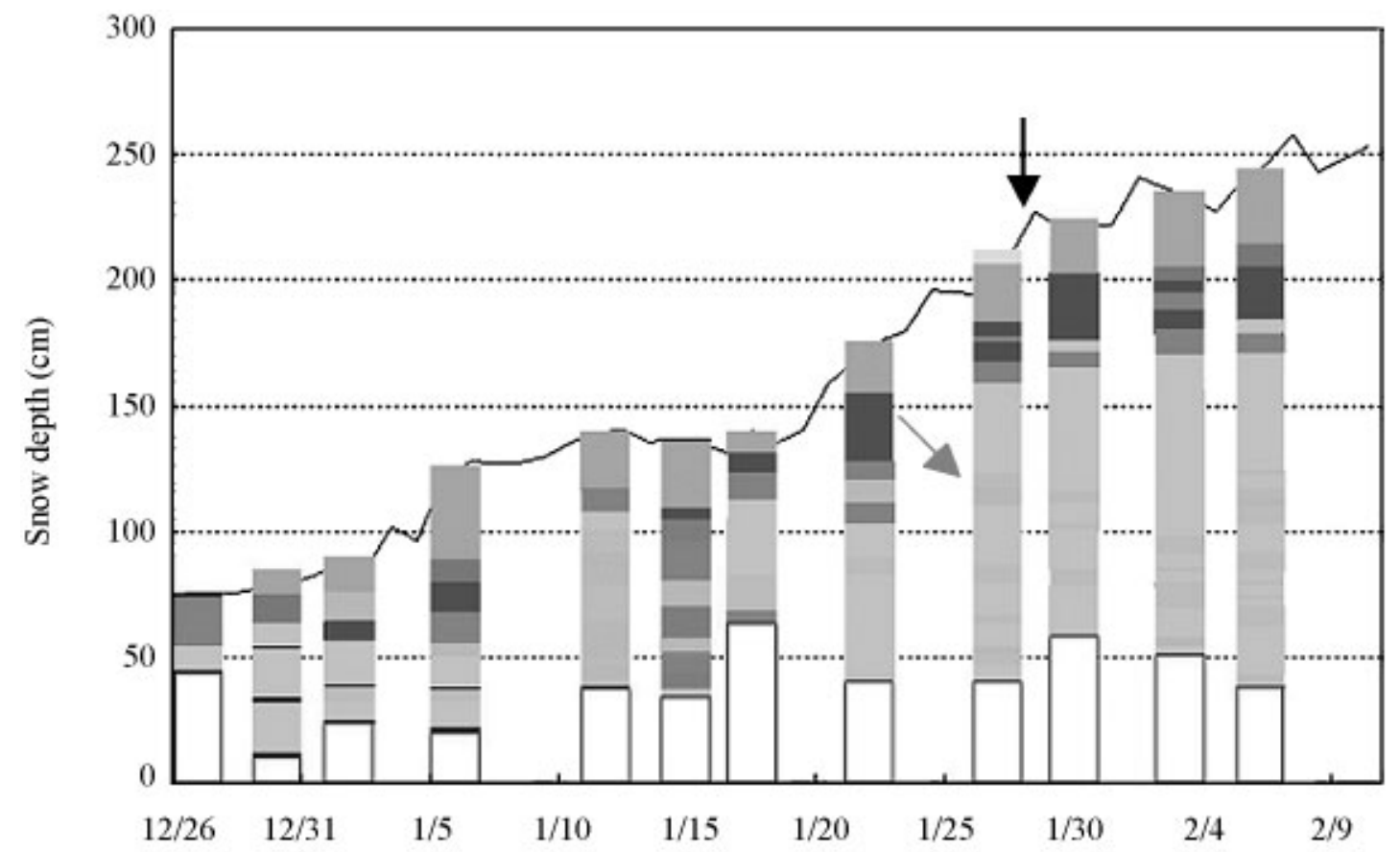

$\mathbf{a}$

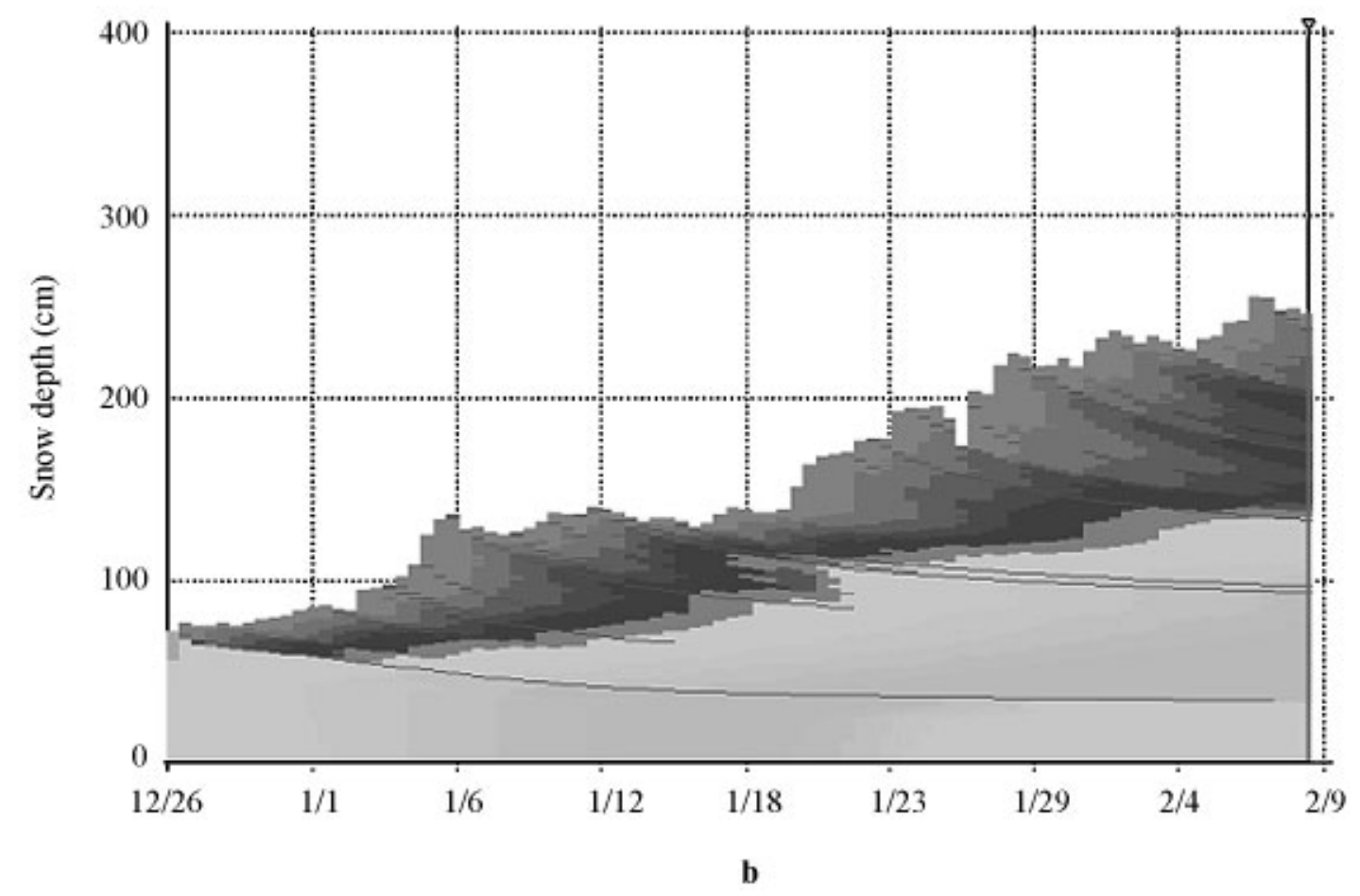

Fig. 3. Snow profiles at Niseko in 1997/98 (dates are month/day). (a) Observed snow profiles. Grain type was not observed in the blank areas. Black arrow indicates the day of an avalanche accident, 28 fanuary. Gray arrow indicates a weak layer. (b) Simulated snow profiles.

the growth of faceted grains and depth hoar, which often form a weak layer and represent typical sliding layers for slab-avalanche release. The temperature profile of snowpack was measured by a thermistor thermometer with a vertical resolution of $5 \mathrm{~cm}$ or more.

Figures $2 \mathrm{a}$ and $3 \mathrm{a}$ show the observed snow profiles in Sapporo 1996/97 and Niseko 1997/98. Snow-pit observations were carried out throughout the snow season in Sapporo and for part of the season in Niseko. As shown in Figure 2a for snow type, depth hoar was observed to form near the surface in Sapporo on 25 January 1997, since the tempera- ture gradient was large due to radiational cooling the previous night. The depth-hoar layer remained until midFebruary. All of the snowpack had changed to melt-freeze grains by the end of February. In March, snow depth decreased as the snowpack melted, and all of the snow had melted by the end of the month.

At Niseko, the snow depth reached $>2 \mathrm{~m}$ in winter 1997/ 98. As indicated in Figure 3a, most of the snow was rounded, and a layer of faceted grains was detected at a height of $120 \mathrm{~cm}$ on 27 January. The next day, 28 January, an avalanche accident occurred. McElwaine and others 
Snow temperature $\left({ }^{\circ} \mathrm{C}\right)$

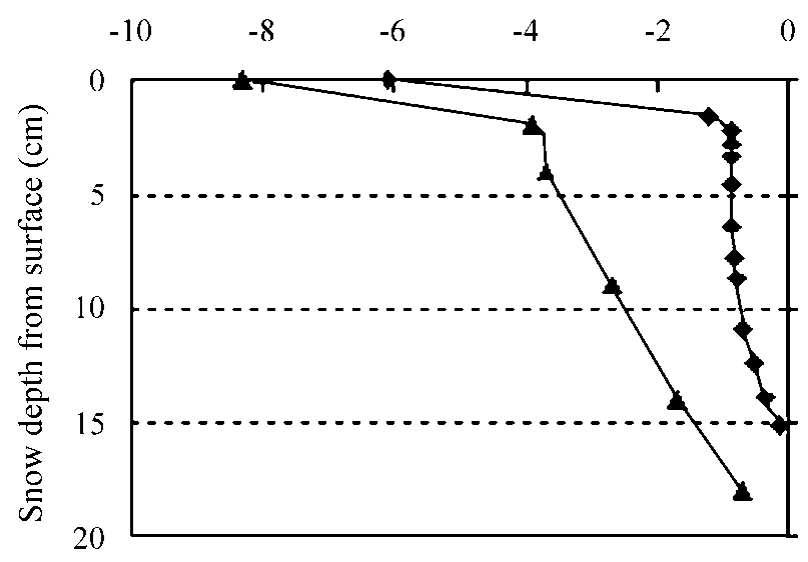

Fig. 4. Simulated and measured snow-temperature profile at 0930 (time zone: Japan) on 25 January 1997 at Sapporo. The top is snow/air interface. The diamonds are simulated snow temperature, and solid triangles are observed temperatures. A considerable temperature gradient was generated at the surface. This temperature gradient was reproduced by SNOWPACK.

(2000) suspected that the weak layer of faceted grains had caused the avalanche.

Depth hoar formed readily in Kitami for 2000/01, since Kitami's winters are colder than Sapporo's and its snow depth is relatively small. The snow here became melt-freeze grains by the beginning of March.

\section{SIMULATIONS}

Figures $2 \mathrm{~b}$ and $3 \mathrm{~b}$ show the snow profiles simulated by the SNOWPACK model. Overall, the simulated snow types agree well with the observed ones in Figures $2 \mathrm{a}$ and $3 \mathrm{a}$. However, some discrepancies are found. For instance, the model predicted less snowmelt than actually occurred, resulting in an overestimation of snow depth for March. This behavior is in agreement with the results of Yamaguchi and others (2004), who investigated the wet-snow zone in Japan. They showed that this behavior is due to the SNOWPACK implicit numerical scheme and that it can be corrected by using a small calculation time-step (e.g. 2 min instead of $15 \mathrm{~min}$ ). In the current version of SNOWPACK, which has just become available, this error has been eliminated.

\section{Sapporo in 1996/97 (Fig. 2a and b)}

In mid-February, the metamorphosis from new snow to rounded grains and faceted grains was well reproduced in the snow layer $20-40 \mathrm{~cm}$ above ground. On 17 February, snowmelt occurred on the surface, which later refroze and formed a layer of ice. This was also shown in the simulation. In the early winter, however, changes to melt-freeze grains were sometimes not reproduced by the model (e.g. on 2 and 14 January).

Although a depth-hoar layer was observed near the snow surface on 25 January, it does not appear in Figure 2b. Radiative cooling of the snow surface from the night of 24 January to the early morning of 25 January generated a strong temperature gradient near the snow surface as shown in Figure 4. This temperature gradient was obtained by
SNOWPACK as well. Thus, there appears to be room to improve the metamorphic processes incorporated in the model.

Although it was observed that all the snow layers had metamorphosed into melt-freeze grains by the beginning of March, in the simulation only the near-surface snow became melt-freeze grains. The reason for this is not that much liquid water remained near the snow surface in the simulation. When volumetric water content $\theta_{\mathrm{w}}$ exceeds the residual water content $\theta_{\mathrm{r}}(0.08$ in SNOWPACK), the excess water is immediately transported into the adjoining layer (Bartelt and Lehning, 2002), so the simulation underestimates the melt rate. This is discussed above.

\section{Niseko in 1997/98 (Fig. 3a and b)}

Overall, the snow structures observed consisted of new snow, rounded grains and faceted grains, as shown in Figure 3a. SNOWPACK reproduced these characteristics fairly well. However, the faceted grain layer that formed at a height of $120 \mathrm{~cm}$ on 27 January was not reproduced. Since this layer may have released the avalanche on the next day (McElwaine and others, 2000), it will be key to determining whether the model can be applied to improve the avalanche prediction in Japan. We discuss this issue more in the next section and try to improve the system.

\section{Kitami in 2000/01}

In mid-December, most of the snowpack metamorphosed into a depth hoar due to the relatively low snow depth (about $20 \mathrm{~cm}$ ) and low air temperature. New snow of $40 \mathrm{~cm}$ then accumulated on the snowpack. The new snow also changed into depth hoar and faceted grains by midFebruary. The model reproduced these processes, although the metamorphosis to depth hoar was somewhat overestimated. The simulation (not shown) also delayed the formation of melt-freeze grains in March.

\section{DISGUSSION}

Although the simulated snow types agreed with the observed ones on the whole, the following discrepancies were found:

1. The estimated snow depth in the snowmelt season was larger than the observed depth. This points to the fact that the model underestimates the snow-cover heat budget, especially during the melt phase. The production of melt-freeze grains was also constently underestimated by the model.

2. Depth hoar and faceted grains that formed in the surface layer and were preserved within the snowpack were not reproduced for some observed layers.

As mentioned above, the correct amount of snowmelt could be obtained with a smaller time-step. In any case, in the snowmelt season, snow depth decreases and a weak layer that could cause the release of a slab avalanche disappears by meltwater infiltration. The correct and timely simulation of wet-snow formulation is important for wet avalanches; however, this is not the focus of this paper. Yamaguchi and others (2004) discuss this problem in more detail.

The SNOWPACK model can estimate the amount of new snowfall from the snow-depth measurement alone 


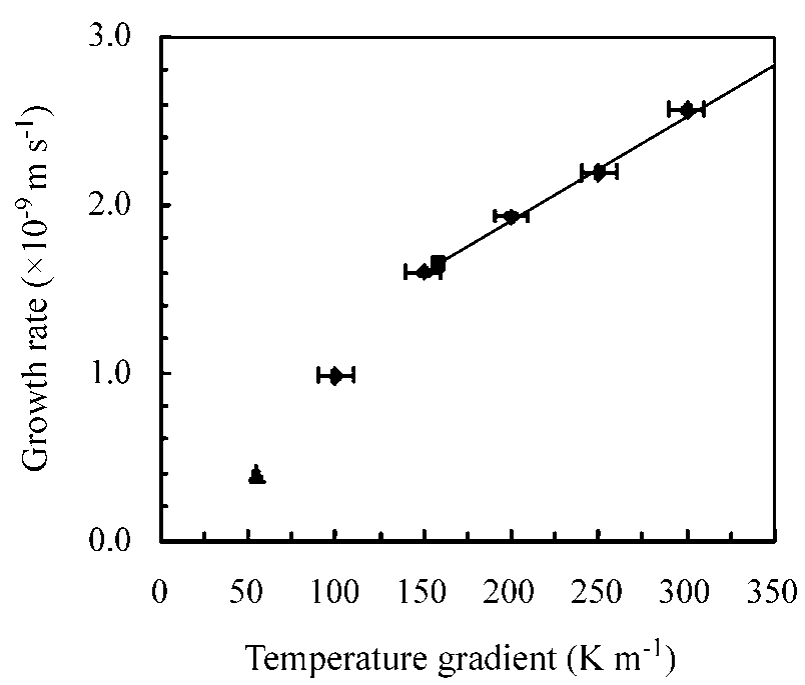

Fig. 5. Growth rate of faceted crystals for various temperature gradients at a constant temperature of $-16^{\circ} \mathrm{C}$ and snow density of $80-100 \mathrm{~kg}^{-3}$. Diamonds show experimental results, and the solid square denotes growth rate during the night of 24-25 January 1990 ( Fukuzawa and Akitaya, 1993). The solid triangle is from Marbouty's (1980) experiment for temperature of $-18^{\circ} \mathrm{C}$ and density of $180 \mathrm{~kg} \mathrm{~m}^{-3}$. Solid line corresponds to Equation (3).

(Lehning and others, 2002b). In this mode of operation, liquid precipitation cannot be taken into account. Therefore, this mode is only recommended for locations where no rain is observed during the main winter season. For the simulations shown above, we ran SNOWPACK in this mode, which may be one reason why melt-freeze grains were not reproduced in the simulation. In fact, it often rains in Japan even in mid-winter. Thus, when air temperature is $>1.0^{\circ} \mathrm{C}$, we input the precipitation data measured by AMEDAS (Automated Meteorological Data Acquisition System operated by the Japan Meteorological Agency) nearby, as rain together with the snow depth. This improves the simulations as discussed below.

Another discrepancy between the observations and the model simulations was the low reproducibility of the depth hoar and the faceted grains close to the surface layer. When the temperature gradient is large, snow metamorphoses into depth hoar or faceted grains. SNOWPACK determines snow type by considering parameters such as sphericity, dendricity and grain-size. The snow metamorphic processes are calculated with the temperature gradient taken into account (Brun and others, 1992). We calculated how long it takes for new snow to metamorphose into faceted grains under a large temperature gradient $\left(150 \mathrm{~K} \mathrm{~m}^{-1}\right)$ and it was found that 12.7 days at $-16^{\circ} \mathrm{C}$ or 5 days at $-5^{\circ} \mathrm{C}$ are necessary. However, actual observation showed that depth hoar formed more rapidly, (e.g. in Sapporo 1996/97). Fukuzawa and Akitaya (1993) carried out an experiment to investigate the quick growth of depth hoar under large temperature gradients $\left(100-300 \mathrm{~K} \mathrm{~m}^{-1}\right)$. They showed that the formation of depth hoar required only about 2 days and that a positive correlation existed between the growth rate of snow crystals and the temperature gradient, as shown in Figure 5. Based on the results of their experiments, the present study incorporated the following empirical expression of the metamorphism process when new snow is subjected to a large temperature gradient.

$$
\begin{gathered}
\dot{d d}=-5.79 \times 10^{-6} \mathrm{~s}^{-1} \quad\left(\frac{\mathrm{d} T}{\mathrm{~d} Z} \geq 150 \mathrm{~K} \mathrm{~m}^{-1}\right) \\
\dot{s p}=-2.89 \times 10^{-6} \mathrm{~s}^{-1} \quad\left(\frac{\mathrm{d} T}{\mathrm{~d} Z} \geq 150 \mathrm{~K} \mathrm{~m}^{-1}\right) \\
\dot{r g}=\left(6.25 \times 10^{-12}\right) \frac{\mathrm{d} T}{\mathrm{~d} Z}+\left(6.48 \times 10^{-10}\right) \mathrm{m} \mathrm{s}^{-1} \\
\left(\frac{\mathrm{d} T}{\mathrm{~d} Z} \geq 150 \mathrm{~K} \mathrm{~m}^{-1}\right),
\end{gathered}
$$

where $\dot{d d}$ is the snow dendricity rate $\left(\mathrm{s}^{-1}\right), s p$ is the snow

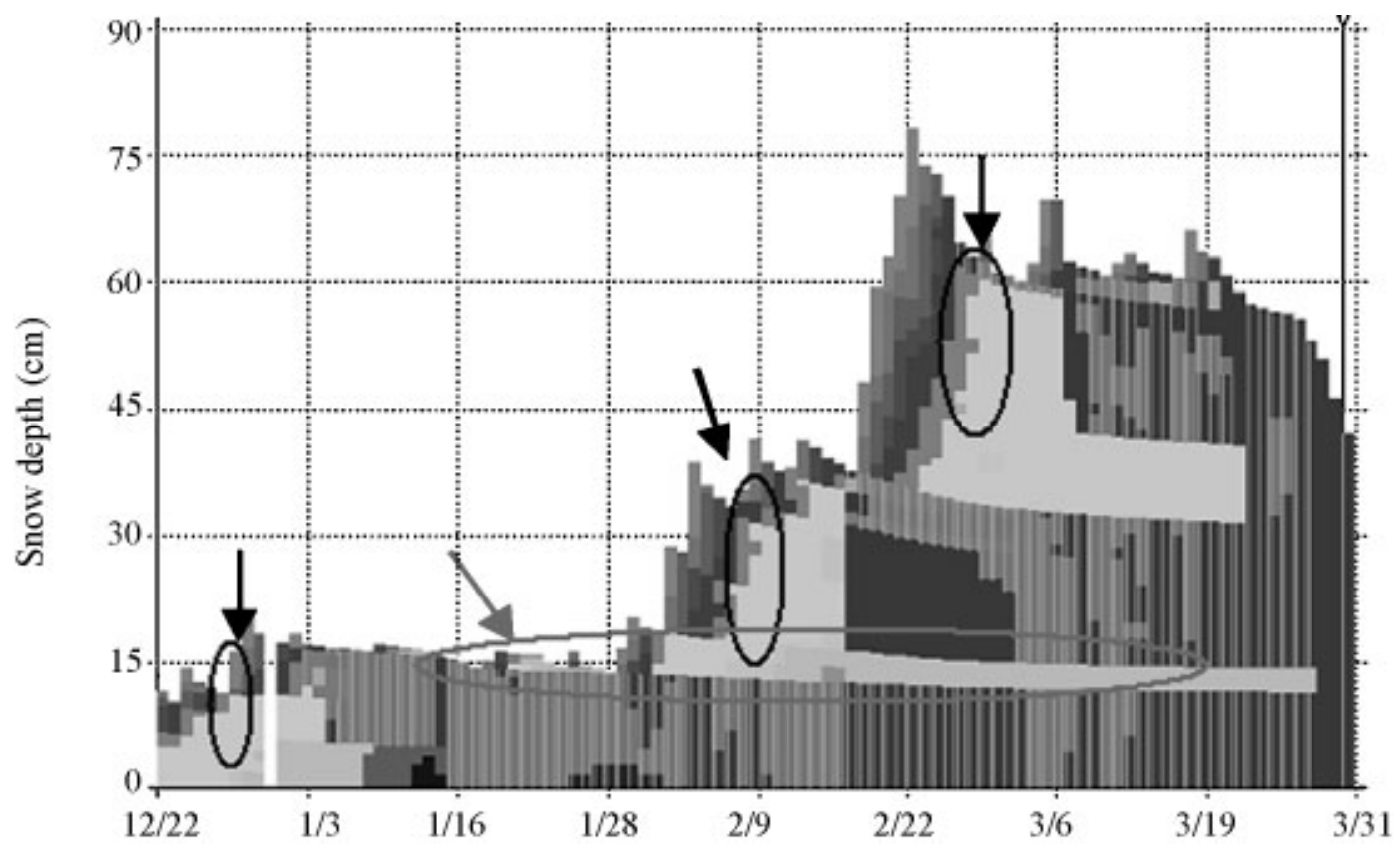

Fig. 6. Improved simulation result at Sapporo in 1996/97. The formation of faceted grains was improved (gray arrow), and the model succeeds in simulating melt-freeze grains in the middle of January and February and at the end of February (black arrows). Dates are month/day. 


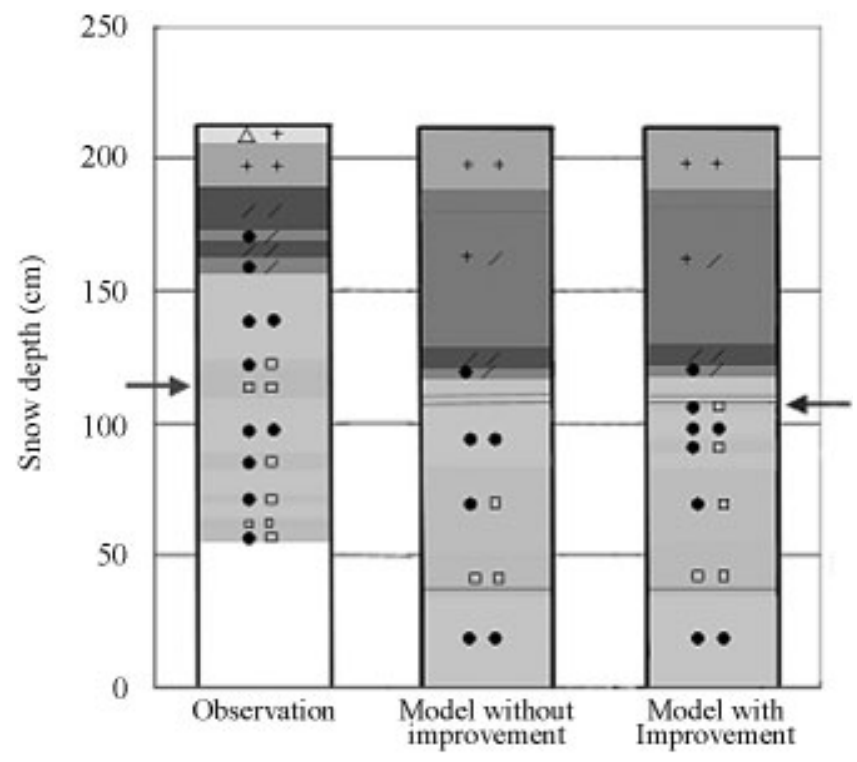

Fig. 7. Comparisons of snow type between observation and simulation on 17 February 1998. Gray arrow indicates weak layers.

sphericity rate $\left(\mathrm{s}^{-1}\right), \dot{r g}$ is the grain growth rate $\left(\mathrm{m} \mathrm{s}^{-1}\right)$ and $\mathrm{d} T / \mathrm{d} Z$ is the temperature gradient $\left(\mathrm{K} \mathrm{m}^{-1}\right)$. It should be noted that both Equations (1) and (2) were derived from the experimental finding that 2 days were necessary to turn snow into faceted snow, and Equation (3) was formulated from the measurement of the crystal growth rate as indicated in Figure 5.

Figure 6 shows the simulated results when we take liquid precipitation into account and incorporate the new growth rate for faceted snow in Sapporo 1996/97. The model succeeds in simulating the melt-freeze grains in the middle of January and February and at the end of February. In the simulations for Kitami 2000/01, the snow changed to meltfreeze grains at the beginning of March, which agreed well with observations. We may therefore reasonably conclude that the input of liquid-precipitation data improved the simulation results of the SNOWPACK model as applied to a moderate temperature region such as Japan's.

The description of the depth-hoar formation was somewhat improved by using the expression based on the experiment by Fukuzawa and Akitaya (1993). In fact, as shown in Figure 6, in Sapporo 1996/97, the model successfully formed faceted grains on 25 January. However, the snow type of this layer was still intermediate between the rounded grains and faceted grains shown in Figure 6, whereas depth hoar at the surface layer was observed in Figure 2a. The model has not been improved enough to completely reproduce depth-hoar formation at the surface layer, for the following reason. Snowmelt occurred until 17 January, when $5 \mathrm{~cm}$ of new snow fell. Then the new-snow layer also metamorphosed into depth hoar (Fig. 2a). On the other hand, SNOWPACK tended to underestimate the amount of snowmelt. This was also the case until 17 January. The model calculates the amount of snowfall according to changes in the snow depth (Lehning and others, 2002b). Since the decrease in the snow depth was underestimated, the amount of new snowfall was also underestimated. New snow on 18 January was estimated as $2 \mathrm{~cm}$ (Fig. 6), whereas the actual observed amount was $5 \mathrm{~cm}$; the new snow quickly changed into depth hoar. In this study, the simulation with a large snow roughness
Table 1. Statistical measures comparing the predicted and observed snowpack parameters at Sapporo in 1996/97

\begin{tabular}{|c|c|c|c|c|c|c|}
\hline & $n$ & $B$ & RMSE & $r$ & $E$ & $d$ \\
\hline \multicolumn{7}{|c|}{ All (December-March) } \\
\hline Temperature & 703 & $-0.61^{\circ} \mathrm{C}$ & $1.17^{\circ} \mathrm{C}$ & 0.82 & 0.46 & 0.86 \\
\hline Density & 1121 & $-36.2 \mathrm{~kg} \mathrm{~m}^{-3}$ & $77.6 \mathrm{~kg} \mathrm{~m}^{-3}$ & 0.78 & 0.45 & 0.78 \\
\hline Grain-size & 1014 & $-0.84 \mathrm{~mm}$ & $1.18 \mathrm{~mm}$ & 0.53 & -0.46 & 0.18 \\
\hline Grain-size (NGR) & 1014 & $-0.79 \mathrm{~mm}$ & $1.15 \mathrm{~mm}$ & 0.52 & -0.38 & 0.25 \\
\hline \multicolumn{7}{|c|}{ Before snowmelt (December-February) } \\
\hline Temperature & 402 & $-0.49^{\circ} \mathrm{C}$ & $1.10^{\circ} \mathrm{C}$ & 0.85 & 0.63 & 0.90 \\
\hline Density & 626 & $-19.7 \mathrm{~kg} \mathrm{~m}^{-3}$ & $65.2 \mathrm{~kg} \mathrm{~m}^{-3}$ & 0.77 & 0.53 & 0.80 \\
\hline Grain-size & 568 & $-0.61 \mathrm{~mm}$ & $0.91 \mathrm{~mm}$ & 0.68 & -0.03 & 0.49 \\
\hline Grain-size (NGR) & 568 & $-0.55 \mathrm{~mm}$ & $0.87 \mathrm{~mm}$ & 0.68 & 0.07 & 0.57 \\
\hline \multicolumn{7}{|c|}{ Considering rain, before snowmelt (December-February) } \\
\hline Temperature & 402 & $-0.29^{\circ} \mathrm{C}$ & $1.05^{\circ} \mathrm{C}$ & 0.86 & 0.66 & 0.92 \\
\hline Density & 626 & $-9.2 \mathrm{~kg} \mathrm{~m}^{-3}$ & $59.1 \mathrm{~kg} \mathrm{~m}^{-3}$ & 0.80 & 0.61 & 0.85 \\
\hline Grain-size & 568 & $-0.58 \mathrm{~mm}$ & $0.89 \mathrm{~mm}$ & 0.70 & 0.04 & 0.54 \\
\hline Grain-size (NGR) & 568 & $-0.53 \mathrm{~mm}$ & $0.85 \mathrm{~mm}$ & 0.70 & 0.11 & 0.68 \\
\hline
\end{tabular}

Notes: $n$ : number of samples; $B$ : mean bias; RMSE: root-mean-square error; $r$ : Pearson's correlation; $E$ : Nash-Sutcliffe coefficient; $d$ : Willmott and Wicks' index of agreement. NGR means incorporation of new growth rate (Equations $(1-3)$ ).

$\left(3 \times 10^{-3} \mathrm{~m}\right)$ was also tested instead of the default value $\left(7 \times 10^{-4} \mathrm{~m}\right)$. Then, the adjusted simulation estimated $5 \mathrm{~cm}$ of new snow on 18 January, and the depth hoar was adequately reproduced.

The reproducibility of faceted grain in Niseko was also improved by substituting the expressions from Equations (1-3). Figure 7 indicates the results of snow-pit observations and simulations for 17 February 1998 (the day before an avalanche broke out), with and without improvement. The weak layer formed at a height of $120 \mathrm{~cm}$, which was reproduced well by incorporating the expressions introduced in this study. Some methods have been developed to quantify the reproducibility of SNOWPACK. Lundy and others (2001) compared the simulation of snow temperature, density, grain-size and grain type with the observation. We also applied their method to the simulation of Sapporo 1996/97, and the results for temperature, density and grain-size are shown in Table 1. Since a large discrepancy was found in the snow depth during the snowmelt period in March (Fig. $2 \mathrm{a}$ and $\mathrm{b}$ ), Table 1 also shows the comparison scores from December to February, during which time the comparison is better. We see that the incorporation of rain effect contributes to the improvement of the simulations. The grain-size was further improved by substitution of Equations (1-3). Lundy and others (2001) verified the grain type introducing Cramer's phi and contingency coefficient. In this study the former value was 0.38 and the latter was 0.71 . These are comparable to the values obtained in Montana, U.S.A. (Lundy and others, 2001). Considerable change of these values was not found through improvement of the model. This points to the fact that the method is not sensitive enough. Lehning and others (2001) developed another measure using normalized distances for all combinations of grain types. This is useful and informative, because we can obtain the time series of agreement scores. Figure 8 shows the score in Sapporo 1996/97. The score in January was improved by incorporation of a new crystal growth rate (Equation (1) into Equation (3)), since the faceted grains are reproduced appropriately. When rain effect was considered, the score 


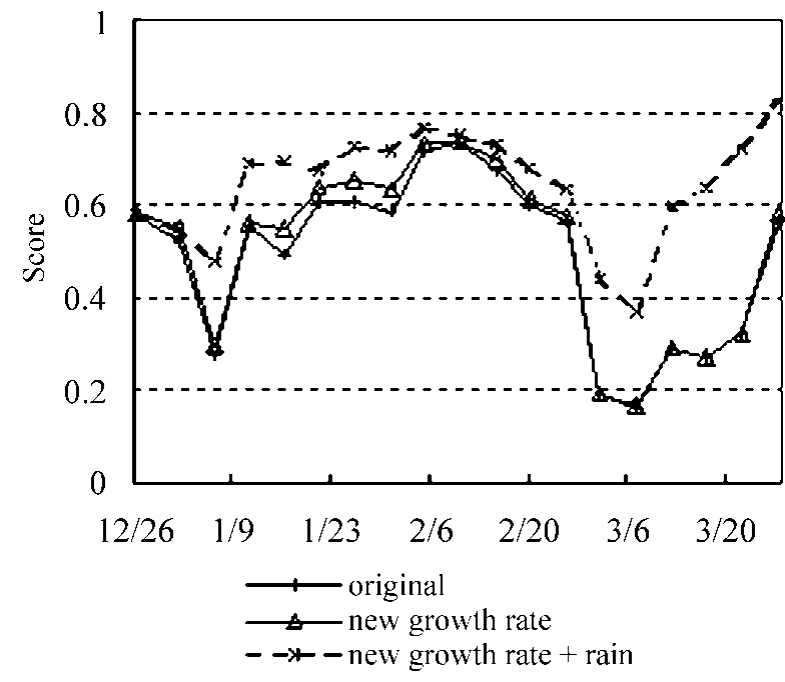

Fig. 8. Time series of agreement scores for snow type between the observed and modeled profiles at Sapporo in 1996/97. Dates are month/day.

increased considerably throughout the winter, which reasonably suggests that winter rain is an important factor in Japan. On the other hand, there was no significant improvement in Niseko 1997/98, although faceted grains were reproduced at $120 \mathrm{~cm}$ above the ground by substituting the new crystal growth rate. This is probably because the layer of faceted grains was too thin and has little effect on the total agreement score. However, it should be noted that the growth of the faceted grains and the formation of a weak layer in the snowpack is a key for the slab avalanche release.

\section{GONGLUSION}

Numerical simulations with SNOWPACK were carried out to confirm the model's applicability to Hokkaido, where temperatures are fairly low and for 3 months the snow surface is usually dry except during occasional periods of rain or above-freezing temperatures. The following results were found:

1. Overall, the simulated snow types agreed fairly well with the observed ones.

2. Decreases in snow depth due to snowmelt were underestimated by the model. This can be solved by a smaller numerical time-step or by a revised version of SNOWPACK (Yamaguchi and others, 2004), which was not available for our study. Since our focus is on the applicability of the model to dry-snow avalanche prediction, we left the snowmelt issue open in this study.

3. Although melt-freeze grains were not always reproduced in the model simulations, the accuracy of the model was greatly improved by taking rain into account.

4. There were a couple of cases when the depth hoar and the faceted grains near the surface were not reproduced by the simulation. However, we made substantial progress by substituting in the expression based on the experiment of Fukuzawa and Akitaya (1993).

In Niseko, 2002/03, an AWS was set up, and systematic observations, including daily snow-pit observations, were begun. Detailed comparisons with the SNOWPACK simulations will also be carried out. It is expected that the research will contribute to the development of an avalanche-forecasting system in Japan.

\section{AGKNOWLEDGEMENTS}

We acknowledge the helpful discussions with T. Ohata, T. Yamada, and T. Sone. Snow datasets at Kitami were obtained as part of the Advanced Earth Observing Satellite (ADEOS II)/Global Imager (GLI) Cal/Val experiment supported by the National Space Development Agency of Japan.

\section{REFERENGES}

Bartelt, P. and M. Lehning. 2002. A physical SNOWPACK model for the Swiss avalanche warning. Part I. Numerical model. Cold Reg. Sci. Technol., 35(3), 123-145.

Brun, E., P. David, M. Sudul and G. Brunot. 1992. A numerical model to simulate snow-cover stratigraphy for operational avalanche forecasting. 7. Glaciol., 38(128), 13-22.

Colbeck, S. C. and 7 others. 1990. The international classification for seasonal snow on the ground. Wallingford, Oxfordshire, International Association of Scientific Hydrology. International Commission on Snow and Ice.

Fukuzawa, T. and E. Akitaya. 1993. Depth-hoar crystal growth in the surface layer under high temperature gradient. Ann. Glaciol., 18, 39-45.

Lehning, M., C. Fierz and C. Lundy. 2001. An objective snow-profile comparison method and its application to SNOWPACK. Cold Reg. Sci. Technol., 33(2-3), 253-261.

Lehning, M., P. Bartelt, B. Brown, C. Fierz and P. Satyawali. 2002a. A physical SNOWPACK model for the Swiss avalanche warning. Part II. Snow microstructure. Cold Reg. Sci. Technol., 35(3), 147-167.

Lehning, M., P. Bartelt, B. Brown and C. Fierz. 2002b. A physical SNOWPACK model for the Swiss avalanche warning service. Part III. Meteorological forcing, thin layer formation and evaluation. Cold Reg. Sci. Technol., 35(3), 169-184.

Lundy, C., R. L. Brown, E. E. Adams, K.W. Birkeland and M. Lehning. 2001. A statistical validation of the SNOWPACK model in a Montana climate. Cold Reg. Sci. Technol., 33(2-3), 237-246.

Marbouty, D. 1980. An experimental study of temperature-gradient metamorphism. f. Glaciol., 26(94), 303-312.

McElwaine, J., A. Hachikubo, M. Nemoto, T. Kaihara, T. Yamada and K. Nishimura. 2000. Observations and simulations of the formation of the faceted snow crystals in the weak-layer of the 1998 Niseko Haru no Taki avalanche. Cold Reg. Sci. Technol., 31 (3), 235-247.

Yamaguchi, S., A. Sato and M. Lehning. 2004. Application of the numerical snowpack model (SNOWPACK) to the wet-snow region in Japan. Ann. Glaciol., 38 (see paper in this volume). 